\title{
Liquid Fuels from Microalgae
}

Donna A. Johnson

Sarah Sprague

\section{August 1987}

Prepared for the Intersociety Energy Conversion

Engineering Conference

10-14 August 1987

Philadelphia, Pennsylvania

Prepared under Task No. 4750.100 FTP No. 656

Solar Energy Research Institute

A Division of Midwest Research Institute

1617 Cole Boulevard

Golden, Colorado 80401-3393

Prepared for the

U.S. Department of Energy

Contract No. DE-AC02-83CH10093 


\section{NOTICE}

This report was prepared as an account of work sponsored by the United States Government. Neither the United States nor the United States Department of Energy, nor any of their employees, nor any of their contractors. subcontractors, or their employees, makes any warranty, expressed or implied, or assumes any legal liability or responsibility for the accuracy, completeness or usefulness of any information, apparatus. product or process disclosed, or represents that its use would not infringe privately owned rights.

\section{Printed in the United States of America \\ Available from: \\ National Technical Information Service \\ U.S. Department of Commerce \\ 5285 Port Royal Road \\ Springfield, VA 22161}

\section{Price: Microfiche A01 \\ Printed Copy AO2}

Codes are used for pricing all publications. The code is determined by the number of pages in the publication. Information pertaining to the pricing codes can be found in the current issue of the following publications. which are generally available in most libraries: Energy Research Abstracts, (ERA); Government Reports Announcements and Index (GRA and I); Scientific and Technical Abstract Reports (STAR); and publication, NTIS-PR-360 available from NTIS at the above address. 


\title{
LIQUID FUELS FROM MICROALGAE
}

\author{
Donna A. Johnson ${ }^{1}$ and Sarah Sprague ${ }^{2}$ \\ ${ }^{1}$ Solar Fuels Research Division \\ Solar Energy Research Institute (SERI) \\ 1617 Cole Boulevard, Golden, Colo. 80401 \\ 2 Department of Energy (DOE) \\ 1000 Independence Avenue, S.W. \\ Washington, D.C. 20585
}

\begin{abstract}
The goal of the DOE/SERI Aquatic Species Program is to develop the technology to produce gasoline and diesel fuels from microalgae. Microalgae can accumulate large quantities of lipids and can thrive in high-salinity water, which currently has no other use. The best site for success was determined to be the U.S. desert Southwest with applications to other warm areas. A technical and economic analysis, "Fuels from Microalgae," demonstrates that liquid fuels can be produced from mass-cultured microalgae at prices that will be competitive with those of conventional fuels by the year 2010. Aggressive research is needed, but the improvements are attainable. Algae are selected for three criteria; tolerance to environmental fluctuations, high growth rates, and high lipid production. From 1982 to 1986, the program collected strains that are twice as tolerant to temperature and salinity fluctuation. Productivity has been increased from $350 \%$ to $500 \%$ (outdoor culture versus indoor culture respectively) and lipid content has also been increased from 100\% to 200\%. The microalgae can be harvested using polymers at a cost of $0.5 \phi-1.5 \notin \mathrm{kg}^{-1}$ dry weight. New program activities include the design and construction of an outdoor test facility in New Mexico and research on converting microalgae lipids into liquid fuels.
\end{abstract}




\section{INTRODUCTION}

The worldwide energy shortage and Arab oil embargo of the early 1970s encouraged many nations to look for new sources of oil, electricity, and gas. Resources such as biomass were often viewed as attractive solutions to the energy problem because of their nondepletable, renewable nature. While the first biomass sources considered were readily available, such as wood or corn, it was apparent that new biomass sources should also be developed, including aquatic species. The current U.S. emphasis is placed on technology for our future energy supplies and not commodities (DOE 1987).

The emphasis of the DOE/SERI Aquatic Species Program is to develop the technology base for large-scale production of lipid-yielding microalgae and conversion of the lipids into liquid fuels (Johnson 1987). The site with the most promising chance of success was determined to be the U.S. desert Southwest with technology spillover to other warm areas of the United States (Figure 1). This technology has the potential of producing between $150-400$ barrels oil acre $\mathrm{yr}^{1}$ based on the growing season.

Microalgae are small unicellular plants that range in size from 1 to $200 \mu \mathrm{m}$. They are unique organisms in that they can accumulate storage lipids in large quantities within their bodies (Figure 2). Historically, microalgae have been grown in mass culture mainly for food production and waste treatment (Benemann et al. 1987). Initial efforts at mass culture of microalgae were directed toward food production, but the hope of producing an abundant, low-cost source of protein has not been realized. However, the most promising early results of mass algae culture have been in the field of sanitary engineering, where microalgae are used to treat wastewater in oxidation ponds. This wastewater technology has been expanded to include protein production and treatment of irrigation water. Microalgae are being grown in Israel, Australia, Mexico, Taiwan, and the United States for high-value products for the health food market; these microalgae include the alga Spirulina (at $\$ 10,000 /$ dry ton) and the vitamin beta carotene (at $\$ 60,000 /$ dry ton). The cultivation of microalgae as a soil conditioner and a food source for culturing fish and shellfish is increasing in importance. More recently, the possibility of using algae as a source of energy received widespread attention after the energy crisis of the 1970s.

The algae can be grown in large outdoor ponds, using the resources of sunlight, saline water, nitrogen, phosphorus, and carbon dioxide. The algae can convert these raw materials into proteins, carbohydrates, and lipids. In the process, they can double their biomass three to five times a day. After a rapid growth phase, the algae are transferred to induction ponds where nutrient limitation is allowed to occur. Under these conditions, many algae stop growth and division and use all their energy to make lipids as storage products to survive. Once the cells have accumulated lipids, they are harvested and the water is recycled back into the growth ponds. The harvested cells then are subjected to an extraction process to remove the lipids. Algal lipids are primarily triglycerides with fractions of isoprenoids, phospholipids, glycolipids, and hydrocarbons. They contain more oxygen and are more viscous than crude petroleum. The two most promising fuel conversion options are transesterification to produce fuels similar to diesel fuels and catalytic conversion to produce gasoline. While microalgal lipids represent the premium energy product, the energy trapped in the other biomass constituents can also be used; e.g., the cell residue after lipid extraction can be digested anaerobically to produce methane and carbon dioxide, which can be recycled for use in the algae production system. 


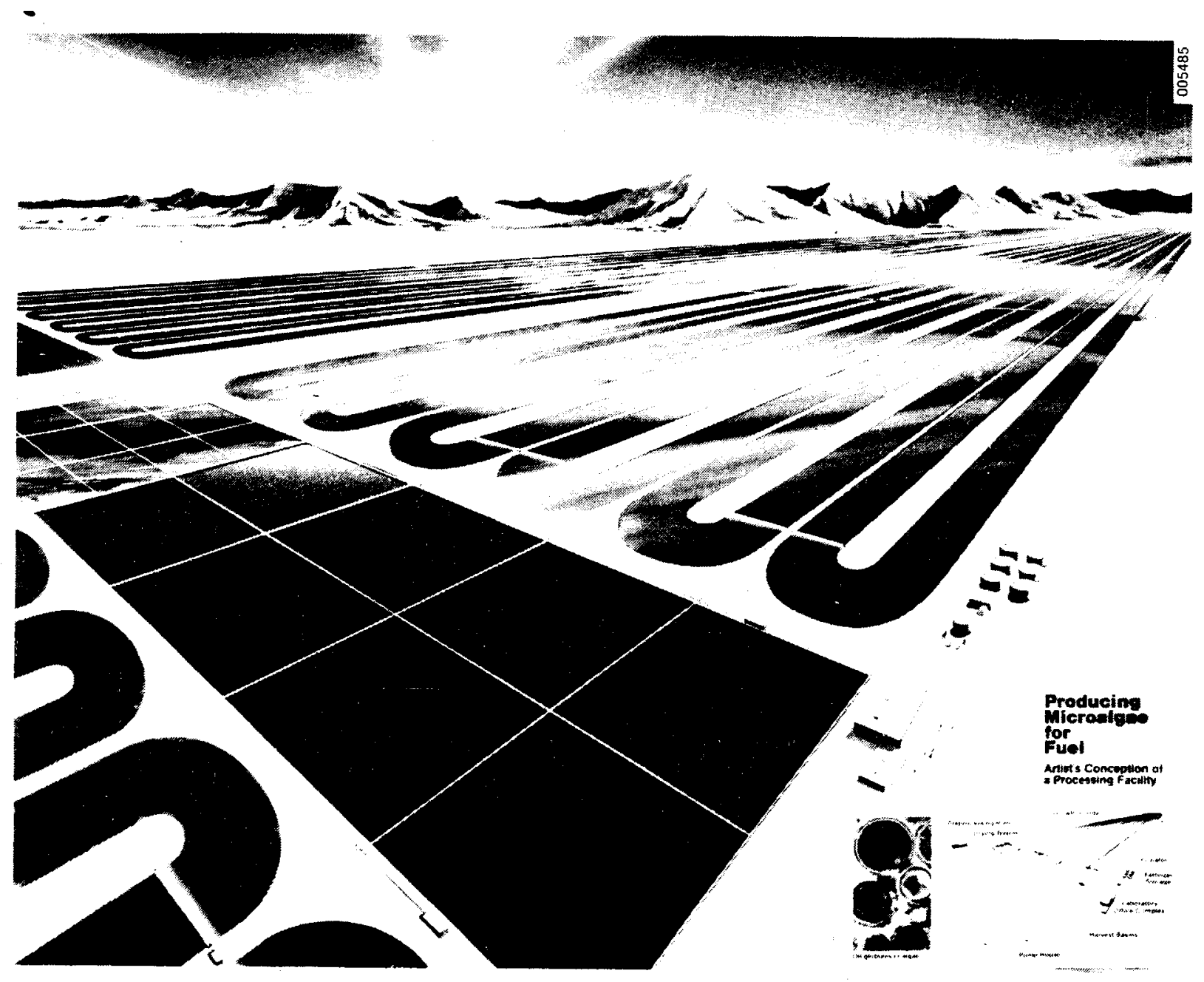

Figure 1. Artist's Concept of Microalgae Fuel Farm in the American Southwest

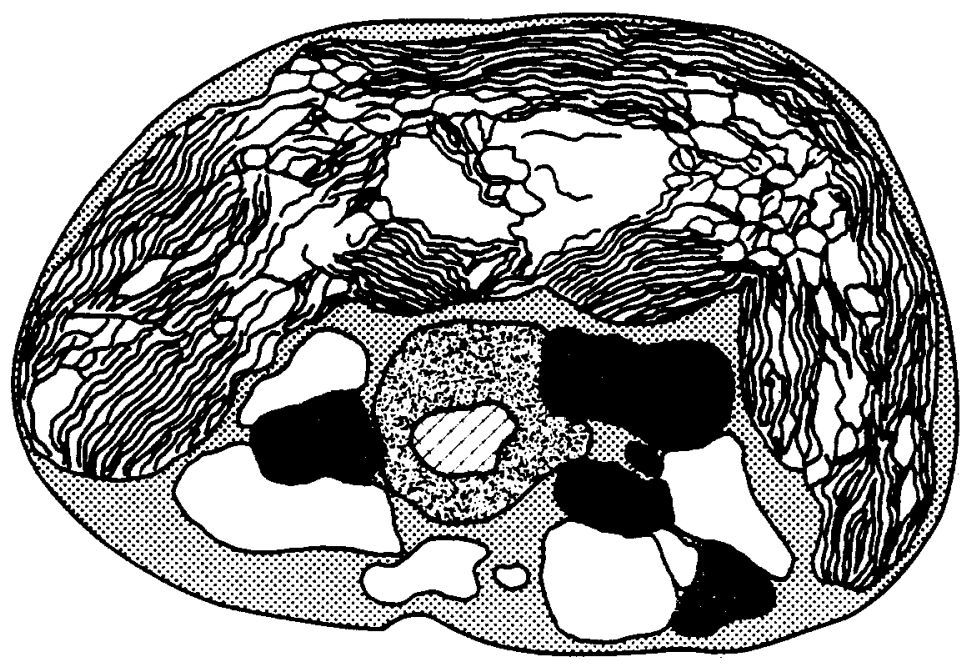

Storage lipids

窟 Membrane bound polar lipids

Figure 2. Micrograph of Algal Cell 
There are four components to large scale algal production and conversion into liquid fuels: 1) microalgae growth and production; 2) engineering design; 3) harvesting; and 4) conversion (Figure 3). The design of a microalgae mass culture system is a synergistic process: the design must be tailored to the characteristics of the culture organism while species must be selected that contribute to economic construction and operation of the facility. Microalgae must be selected that are environmentally tolerant, have high growth rates, and produce large quantities of lipids. In addition, the choice of a suitable species affects harvesting ease. The types of lipids that the algae produce will determine the conversion methods. Thus, all four areas of development are highly interactive with each other. Each of these four areas of research and technology development will be discussed in detail in the remainder of the paper.

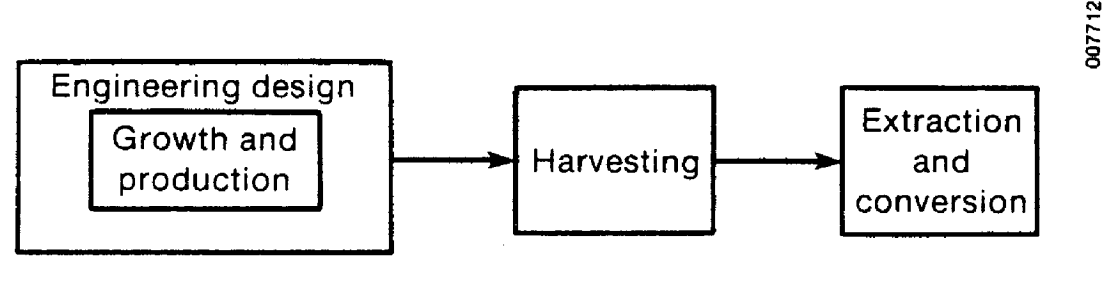

Figure 3. Four Stages Necessary to Produce Liquid Fuels from Microalgae

\section{MICROALGAE GROWTH AND PRODUCTION}

As mentioned in the previous section, for this technology to be successful it is necessary to cultivate microalgae species that are tolerant to fluctuating temperatures and salinity, have high growth rates and can produce large quantities of lipids. A past research effort collected various algal strains from diverse geographical locales and ecological niches. By 1986, over 3000 microalgal strains had been collected. A major screening effort is now under way to reduce these to the best $10-25$ strains that have the characteristics described above.

The most promising strains collected are Bacillariophyceae (diatoms), Chlorophyceae (green algae), and Eustigmatophyceae (Eustigmatophytes). The program has identified several strains that tolerate severe environmental fluctuations in temperature and salinity. Strains of microalgae used by the program in 1982 exhipited temperature tolerances of $15^{\circ}-25^{\circ} \mathrm{C}$ and salinity tolerances of $20-40 \mathrm{mmho}^{-1}$. With intensive collection efforts nationwide, the program now has strains that can tolerate $10^{\circ}-35^{\circ} \mathrm{C}$ and 10-70 mmho $\mathrm{cm}^{-1}$ (for comparison, seawater is approximately $35 \mathrm{mmho} \mathrm{cm}^{-1}$ salinity).

Research efforts are continuing to increase the rates of productivity of microalgae to enhance yields of energy products. We are conducting research in both laboratory and outdoor cultures to identify species and to develop culture management strategies that improve productivity rates. Rates of productivity of algae are higher than those of most other plants. Table 1 shows the productivity rates of many other plants and indicates the order of magnitude greater productivity we expect to obtain in the outdoor culture ponds. This level of productivity has been met in the laboratory and in small outdoor test ponds on a short-term basis. On a long-term basis we can sustain productivity rates at $70 \%$ of the target. 
The goal of the third major research area in production is to increase the amount of lipid in each algal cell. Significant increases have been made in quantity, from $20 \%$ of cell content in 1982 to $66 \%$ in the laboratory and $40 \%$ outdoors. Our target is $60 \%$ lipid in outdoor cultures. We are able to induce lipid accumulation by removing nitrogen or silica (major nutrients required for growth) from the media. During this period of stress, some algae will begin to build up reserves of carbohydrates while others will accumulate lipids. In addition to nutrients, temperature, $\mathrm{pH}$, inorganic carbon and light can all affect the cell's lipid quantity.

Table 1. Comparative Productivity Rates in Different Plant Communities (adapted from Whittaker 1975)

\begin{tabular}{lc}
\hline Plant Community & $\mathrm{g} \mathrm{m}^{-2} \mathrm{yr}^{-1}$ \\
\hline Continental: & 2200 \\
Tropical rain forest & 1200 \\
Temperate deciduous forest & 700 \\
Woodland and scrubland & 90 \\
Desert and semidesert scrub & 650 \\
Cultivated land & \\
Marine: & 125 \\
Open ocean & 360 \\
Continental shelf & 2500 \\
Algal beds and reefs & 12500 \\
Microalgae ponds & \\
\hline
\end{tabular}

To improve lipid yields in microalgae, we must understand the physiological and biochemical basis for partitioning photosynthetically fixed $\mathrm{CO}_{2}$ into lipids. The rate of lipid synthesis and final lipid yield will depend on the availability of carbon for lipid synthesis and the actual levels and activities of the enzymes used for lipid synthesis. Conditions such as nitrogen deficiency that induce the accumulation of lipid by algae often drastically reduce the capacity of photosynthetic $\mathrm{CO}_{2}$ fixation. Low lipid yields could result either from an absence of carbon skeletons or from low levels of enzymes. Improvements in lipid yield can be achieved only when the limiting factors have been determined.

Research efforts are continuing in order to determine the pathways of lipid biosynthesis in algal cells, especially in the cytoplasm, chloroplast, and mitochondrion. Each pathway possesses potential lipid triggers. Once the trigger is determined, biochemical and genetic engineering techniques can be used to increase the lipid yield of promising algal strains.

To date, no single microalgae strain has been found that exhibits environmental tolerance, high productivity, and high lipid yield. All three characteristics are necessary in one organism to meet program goals. For this reason, work has begun on developing genetic engineering methods so that by 1990 when the program has reduced its strains to the best 10 to 25 , the methods to modify these organisms genetically will be available. 
We are working in three areas of genetic engineering research: 1) classical genetic manipulation methods; 2) intraspecific genetic variability; and 3) vector and protoplast fusion methodology. Each research area provides different parts of the total knowledge that we will need to genetically engineer a better organism.

\section{ENGINEERING DESIGN}

Growth conditions in algae mass cultures can be divided into two categories: those dictated by the location of the culture and those based on culture management strategy. Location-related variables include insolation, evaporation, rainfall, temperature, and wind velocity. Variables that can be managed include salinity, nutrient concentration, carbon dioxide concentration, culture mixing, culture aeration, and residence time of the population.

Growth conditions dictated by the facility's location will be among the prime considerations in siting the production facility. The DOE/SERI program has been based on the assumption that it will be necessary to locate a production facility in an area that receives large amounts of sunlight and has relatively warm temperatures. To be economically feasible, the facility must be located in an area that receives $5000 \mathrm{kcal} \mathrm{m}^{-2} \mathrm{~d}^{-1}$ and has greater than 200 frost-free $\mathrm{d} \mathrm{yr}^{-1}$. This limits large scale production to the southern United States (Figure 4).

Sunlight drives the production of biomass; therefore, ideal production systems will be located in areas that receive high insolation. It is also necessary to consider the tradeoffs involved in achieving high insolations. If the costs of land, raw materials, or operation are significantly increased at a location with high insolation, siting solely by the solar input may be disadvantageous.

Many other production conditions in outdoor systems are dictated by the engineering design and the management strategy. For example, if saline water is used, the salinity can be maintained at any given range governed by the algal species selected. Nutrient concentrations, carbon dioxide concentration, culture mixing, culture aeration and culture turnover can also be selected.

Three designs were examined for the large scale production of microalgae. These included open ponds, raceways and enclosed tubes. The proposed costs for construction and operation of these three systems is shown in Table 2. Since all costs need to be kept to a minimum for the feedstock to be produced inexpensively, thereby producing an economic liquid fuel, open pond systems were chosen as the facility plan for outdoor production (Figure 5).

Table 2. Capital Construction Costs for
Three Different Algal Production
Systems

\begin{tabular}{lc}
\hline Engineering Design & Cost $(\$ / \mathrm{ha})$ \\
\hline Open ponds & 76,000 \\
Raceways & 161,000 \\
Enclosed tubes & 348,000 \\
\hline
\end{tabular}




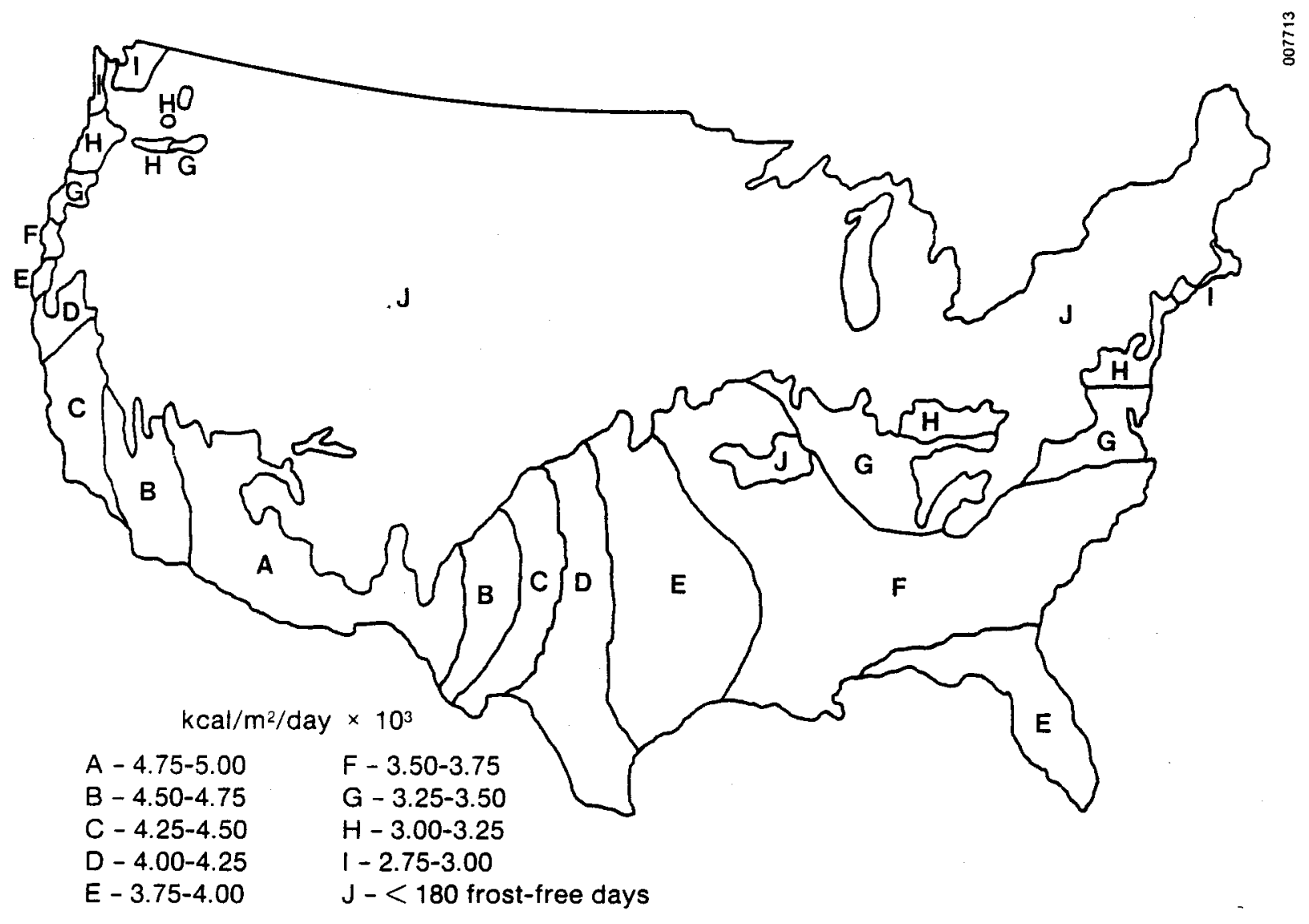

Figure 4. Solar Radiation in the Unjted States Where There are Greater than 180 Frost-free $\mathrm{d} \mathrm{yr}^{-1}$

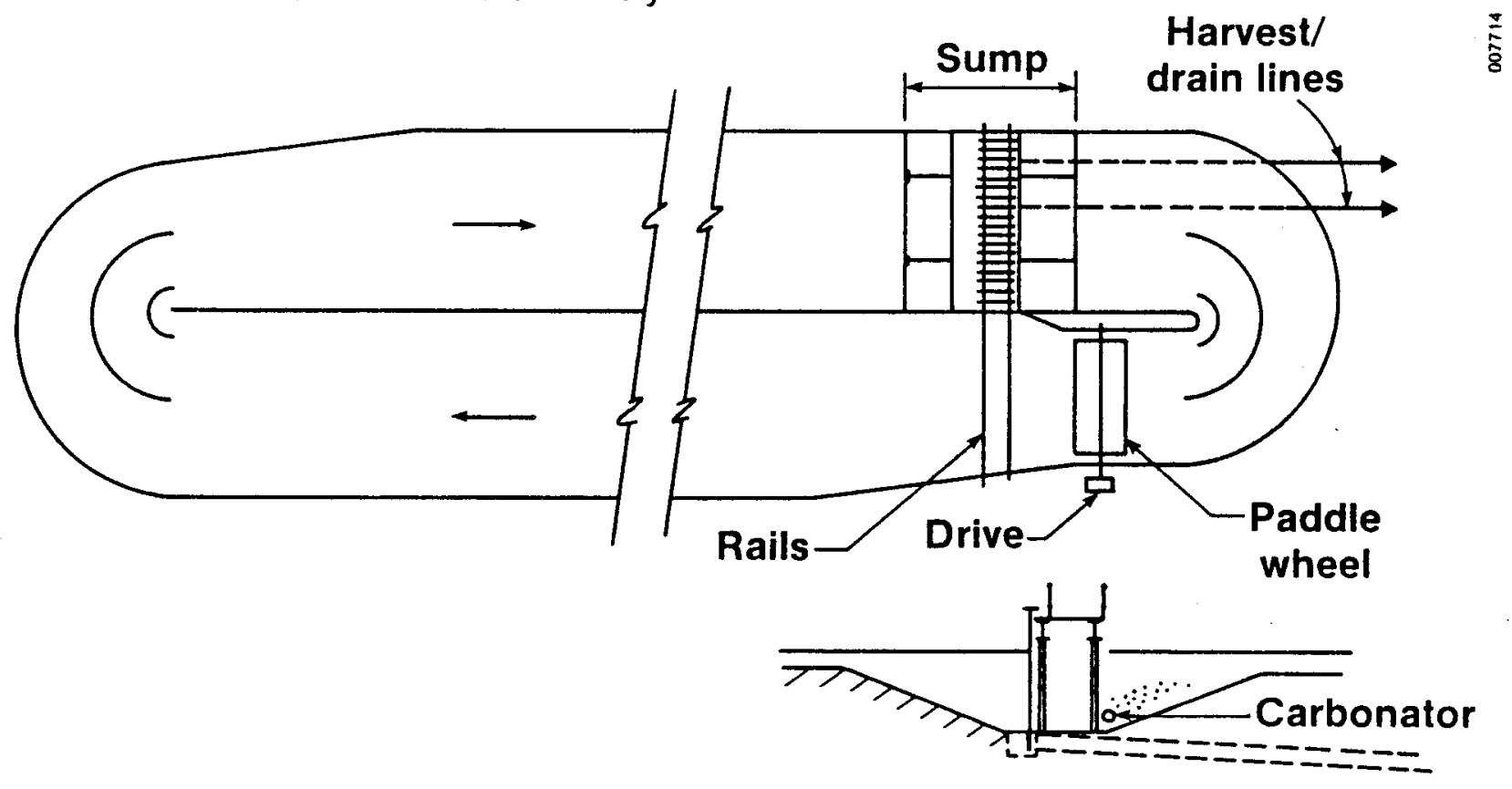

Sump Section

Figure 5. Open Pond Design for Large Scale Microalgae Production (from Weissman and Goebel 1987) 
Using the open pond design, a microalgae outdoor test facility (OTF) is currently being constructed in Roswell, New Mex. for the Aquatics Program. Microbial Products, Inc., California, is designing, constructing and will operate the facility. The OTF will allow the program to evaluate outdoor production performance of microalgae productivities and to examine the problems and potential of scaling-up and operating large microalgae production systems. This facility will allow the program to begin evaluations using saline groundwater in the desert Southwest. The plan that is to operate calls for six $3 \mathrm{~m}^{-2}$ ponds for small scale screening of microalgae growth, two 0.1 ha ponds for large scale replicate or control versus manipulated experiments, and one 0.5 ha pond to study scaleup problems. The facility will be built over a three-year period as funding is available. Both biological and engineering assessments of microalgae production systems will be performed at the OTF. In addition, after several years of operation, a detailed economic analysis shall be done to provide state-of-the-art economics for large scale production costs.

\section{HARVESTING}

After the cells are grown, they must be separated from the water efficiently and economically. Techniques for harvesting microalgae include settling or flotation, centrifugation, and filtration. These processes are aided by cell flocculation, either through the addition of chemical flocculants or through culture autoflocculation. Flocculation causes the cells to become aggregated into larger clumps which are more easily filtered and/or settle more rapidly. The ease in harvesting the algae depends primarily on the organism's size, which determines how easily the species can be settled and filtered. The most rapidly growing algal species are frequently very small, and often motile unicells. These are the most difficult to harvest. Thus, it is necessary to maintain an effective interaction between the development of harvesting technologies and the selection of algal species for mass culture.

With current techniques and instrumentation, all microalgae can be harvested with polymers, although this is not economical. Polymer harvesting is technically feasible but different algae need different polymers. The amount of polymer increases as the clarification requirement becomes more stringent, making it more cost effective not to require greater than $85 \%$ removal. With the most suitable polymers and appropriate application techniques, harvesting can be accomplished for polymer costs of $0.5 \notin-1.5 \notin \mathrm{kg}^{-1}$ dry mass, with removal efficiencies of $85 \%-95 \%$. Polymers with higher rigid backbones are less affected by the salt concentration and are recommended as flocculants of microalgae in saline water.

Another method of harvesting that has been examined is chemical flocculation. Flocculant dose was reduced $75 \%$ by recyling the precipitant following flocculation back into the mixing-flocculation chamber. Using three flocculation cycles reduced the required chemicals and removed $90 \%$ of the microalgae from the water.

\section{CONVERSION}

Analysis of fuel conversion options for microalgae biomass has demonstrated that the promise of microalgae for fuel production is best realized through using conversion processes based on cellular lipids. The two most promising fuel conversion options are transesterification to produce fuels similar to diesel fuels and catalytic conversion to produce gasoline. Although microalgae lipids represent the premium energy product, the energy trapped in the other biomass constituents can also be used; e.g., the cell residue after lipid extraction can be anaerobically digested for the production of methane and carbon dioxide. 
We do not believe that the algal lipids can be used directly as a fuel either alone or blended with crude petroleum. Algal lipids contain approximately $10 \%$ oxygen, while crude petroleum contains essentially no oxygen. The oxygenates would react at the high temperatures used in crude distillation and cause polymerization or other undesirable reactions.

Research is just beginning on the processes to extract and convert algal lipids into gasoline and diesel fuels. It appears that bioconversion can occur through the enzymes that occur naturally in the algae. If the algae are left for $16-24 \mathrm{~h}$ at $20^{\circ} \mathrm{C}$, more than one-half of the triglycerides are converted to fatty acids. This is the first step required in the conversion process to liquid fuels and may be an economical method, since no chemicals are required.

A second and unusual method that is being explored is using pyrolysis over a zeolite catalyst to convert the entire algae cell into aromatic hydrocarbons. Results are not yet available for this technique. Future research efforts of the program will focus on increasing the amount of research into lipid-to-fuel conversion.

\section{SUMMARY}

A technical and economic analysis, "Fuels From Microalgae" (Neenan et al. 1986), demonstrates that liquid fuels can be produced from mass-cultured microalgae at prices that will be competitive with those of conventional fuels by the year 2010. Aggressive research is needed in the areas of microalgae growth and production, engineering design, harvesting, and conversion. We believe that the research improvements necessary to produce an economic fuel are all attainable. Almost all the required improvements have been successfully accomplished on an individual basis in small-scale controlled conditions.

\section{BIBLIOGRAPHY}

Benemann, J. R., D. M. Tillet, and J. C. Weissman, 1987, "Microalgae Biotechnology," Trends in Biotechnology, Vol. 5, pp. 47-53.

Department of Energy, 1987, Energy Security: A Report to the President of the United States, Washington, D.C.: Department of Energy.

Johnson, D., 1987, FY 1986 Annual Report of the Aquatic Species Program, SERI/SP-2313071, Golden, Colo.: Solar Energy Research Institute.

Neenan, B., D. Feinberg, A. Hill, R., McIntosh, and K. Terry, 1986, Fuels from Microalgae: Technology Status, Potential and Research Requirements, SERI/SP-231-2550, Golden, Colo.: Solar Energy Research Institute.

Weissman, J. C., and R. P. Goebel, 1987, Design and Analysis of Microalgal Open Pond Systems for the Purpose of Producing Fuels, SERI/STR-231-2840, Golden, Colo.: Solar Energy Research Institute.

Whittaker, R. H., 1975, Communities and Ecosystems, 2nd edition, New York, N.Y.: MacMillan Publishing Company. 